\title{
Long Term Follow up of the Solyx Single Incision Sling in the Treatment of Female Stress Urinary Incontinence (SUI)
}

\author{
Scott Serels $^{1^{*}}$, Michael Douso ${ }^{2}$ \\ ${ }^{1}$ Bladder Control Center of Norwalk, Norwalk, USA \\ ${ }^{2}$ Capital Regional Women's Health, Tallahassee, USA \\ Email: scottserels@hotmail.com
}

Received January 11, 2014; revised February 3, 2014; accepted February 10, 2014

Copyright (C) 2014 Scott Serels, Michael Douso. This is an open access article distributed under the Creative Commons Attribution License, which permits unrestricted use, distribution, and reproduction in any medium, provided the original work is properly cited. In accordance of the Creative Commons Attribution License all Copyrights (C) 2014 are reserved for SCIRP and the owner of the intellectual property Scott Serels, Michael Douso. All Copyright (C) 2014 are guarded by law and by SCIRP as a guardian.

\begin{abstract}
Objectives: The Solyx System was developed to be easier and safer to use than other slings. It was the objective of this study to retrospectively assess the long-term safety and efficacy of the Solyx ${ }^{\mathrm{TM}}$ SIS Sling System. Methods: After IRB approval and informed consent, chart reviews with follow up phone questionnaires of 69 subjects implanted with the Solyx Sling were collected at 2 sites. All of the patients had SUI and had urethral hypermobility with a q-tip test of $>30$ degrees. All subjects underwent surgery from 12/2008 to 01/2010 with a mean follow up of 43 months (range 39 - 49). Subjects included in this data collection had a mean age of 67 years (range 30 - 87). The dominant type of incontinence within the study patients was SUI while 17/69 (25\%) of the subjects also had a component of urge incontinence. 38/69 (55\%) of study patients had concomitant procedures. Results: Longterm Solyx results showed 64/69 (93\%) of patients were subjectively dry by questionnaire and were satisfied with their outcome. 63/69 (91\%) would have the procedure again. There were 4 cases of denovo urge incontinence and 2 reports of transient retention. There were no serious adverse events including no bladder, bowel, vessel or nerve perforations and no erosions or extrusions. No pain was reported that was attributed to the implant. Conclusions: Chart review with follow phone questionnaires indicated that the Solyx Sling was a safe, efficacious and less-invasive option for patients requiring SUI surgery and that these results were sustainable for an average of 43 months.
\end{abstract}

\section{KEYWORDS}

Single Incision Sling; Stress Urinary Incontinence

\section{Introduction}

The treatment of Stress Urinary Incontinence (SUI) has changed dramatically as a result of the contributions of Ulmsten and Petros. They demonstrated to the urogynecology and urology communities that one could correct SUI by using a piece of polypropylene mesh anchored via the retropubic space [1]. However, retropubic correction of SUI with a TVT does have inherent risks such as bowel, vascular, and bladder injury [2,3]. These complications are due to the blind passage of trocars through the retropubic space. In order to reduce the surgical complications of tension free mid-urethral slings, minimize invasiveness, and continue to have successful results, the

*Corresponding author. single incision sling (SIS) was developed.

The SIS technique allows a small piece of polypropylene mesh to be introduced via a single vaginal incision without skin incisions. Single incision slings were first introduced approximately 5 years ago with lengths of $8-8.5 \mathrm{~cm}$ and many did not include any specific anchor to fixate the sling as scarring developed. In addition, techniques for placement of previous single incision slings were not uniform. Initial study results on single incision slings have been mixed [4] and preliminary findings regarding their efficacy were not comparable to those seen with transobturator and retropubic slings. More recent retrospective and prospective studies on the use of second generation single incision sling systems have demonstrated minimal morbidity and relatively high 
efficacy [5,6].

The Solyx ${ }^{\mathrm{TM}}$ sling is a single incision midurethral sling, which is $9 \mathrm{~cm}$ in length and has nonabsorbable polypropylene darts on each end of the sling. The length of the Solyx ${ }^{\mathrm{TM}}$ sling is long enough to support the midurethra but not too long that it would enter the retropubic space, perforate muscles of the lower extremity, or approach the obturator nerves. The sling is placed in the obturator muscle tissue via an introducer that allows for precise placement. Polypropylene darts anchor the sling in the obturator muscle until tissue in growth permanently fixes the mesh in place. The technique for placing this sling has been standardized to permit reproducible placement into the obturator internus muscle. The goal of this study is to retrospectively assess the long-term safety and efficacy of the Solyx ${ }^{\mathrm{TM}}$ SIS Sling System in women with SUI.

\section{Materials and Methods}

A retrospective trial evaluating the safety and tolerability of the Solyx ${ }^{\mathrm{TM}}$ sling was conducted at Norwalk Hospital and Capital Regional Women's health medical center (December 2008 - January 2010). Institutional Review Board approval was obtained at both institutions. The study population included women with SUI and no evidence of detrusor instability that elected to undergo surgical treatment. All patients underwent preoperative urodynamic testing, and had urethral hypermobility defined as a Q-tip test angle of $\geq 30$ degrees from the parallel with straining or a change of 30 degrees or more with straining. Sixty-nine subjects meeting all of the inclusion/exclusion criteria and who underwent surgery with the Solyx ${ }^{\mathrm{TM}}$ SIS System [Figure 1] for treatment of stress urinary incontinence were enrolled in the clinical trial. The charts were reviewed retrospectively and follow phone questionnaires were obtained (Figure 2).

\section{Surgical Technique}

IV antibiotics were administered pre-operatively. Patients were placed in the dorsal lithotomy position and general, regional, or local anaesthesia was administered at the discretion of the operating surgeon and anaesthesiologist. The bladder was entirely drained and a $1-2 \mathrm{~cm}$ incision was made in the anterior vaginal wall at the level of the midurethra. The vaginal epithelium was then bilaterally undermined and separated from the endopelvic fascia using sharp dissection to the level of the inferior pubic rami, creating a pathway for delivery of the sling arms. The tip of the delivery device was placed into the mesh tip carrier. The deployment mechanism (consisting of a plastic handle and stainless steel trocar) was inserted into the dissected pathway at a 45 degree angle and used to pass the distal arm anchors through the obturator internus muscle behind the pubic ramus. The anchors were advanced until the midline marking on the trocar reached the patient's midline under the urethra. Once positioning was optimized, the anchoring carrier was deployed from the trocar by stabilizing the delivery trocar with one hand and pulling the device handle with the opposite hand. This was repeated in similar fashion on the opposite side.

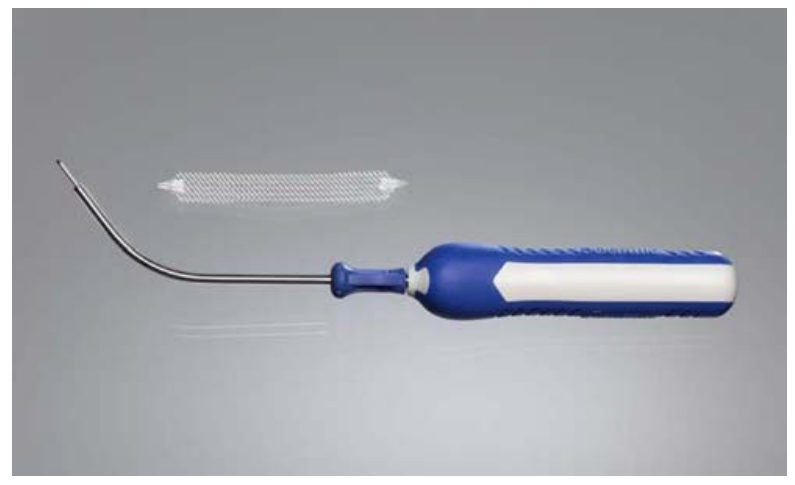

Figure 1. Solyx ${ }^{\mathrm{TM}}$ SIS system.

Patient name/ initials:

Age:

Were they part of original Solyx study (circle one): yes or no

Date of Original Surgery:

Procedure Performed along with sling (if none then type none):

PHONE QUESTIONS TO PATIENT:

Are you happy with incontinence procedure (circle one): yes or no

Would you do procedure again (circle one): yes or no

Are you dry to your satisfaction of leakage with increases in abdominal pressure (circle one): yes or no

Do you have new onset urgency/urge incontinence (circle one): yes or no. If yes do you take medication for OAB (circle one): yes or no

Have you needed any further SUI therapy (circle one): yes or no

Are you currently using pads for SUI (circle one): yes or no

Figure 2. Solyx long term prospective questionnaire. 
In effect, the mesh carriers, acting as mesh anchors were deposited into the obturator muscle tissue and the sling was brought to rest at the level of the midurethra without tension. The surgeon verified that the mesh was not twisted prior to deployment of the second mesh arm, and that a small instrument could easily be passed between the urethra and the mesh once both arms were deployed. Bladder integrity was verified with cystoscopy in all patients after placement of the sling. The vaginal incision was then sutured closed with delayed absorbable suture.

The charts of the 69 patients were then reviewed and data obtained. Each patient was called and follow up phone questions were asked as shown in the questionnaire in Figure 1.

\section{Results}

Sixty-nine patients underwent placement of the Solyx ${ }^{\mathrm{TM}}$ sling by one of two experienced surgeons. Mean patient age was 67.0 years; (range 30 - 87 years) and mean parity was 2.7 (range 1 - 4). All patients were diagnosed with stress urinary incontinence. All patients had preoperative urethral hypermobility. A total of 38 patients had concomitant procedures including cystocele repair with mesh augmentation, total vaginal hysterectomy and cystocele repair with mesh augmentation, and combined anterior repair with mesh and posterior repair.

Results were based on a mean follow-up of 43 months (range 39 - 49 months). The dominant type of incontinence within the study patients was SUI while 17 (25\%) of the subjects also had a component of urge incontinence. 38/69 (55\%) of study patients had concomitant procedures.

Long-term Solyx results showed 64/69 (93\%) of patients were subjectively dry by questionnaire and were satisfied with their outcome. Efficacy of the Solyx ${ }^{\mathrm{TM}}$ system was also based on objective standing cough stress testing at a fill volume of $300 \mathrm{ml}$. The cough test correlated one to one with the patients that were subjectively dry as determined by the subjective questionnaire. 63/69 (91\%) would have the procedure again. There were 4 cases of denovo urge incontinence and 2 reports of transient retention. There were no serious adverse events including no bladder, bowel, vessel or nerve perforations and no erosions or extrusions. No pain was reported that was attributed to the implant.

\section{Discussion}

The goal of the tension free midurethral sling is to improve the quality of life in women without causing significant morbidity and complications. Furthermore, a sling procedure should have a lasting effect that does not deteriorate over time. There have been some short-term results with the single incision sling technology, but their long-term efficacy has been debated. It is the goal of this paper to improve the perception of the Solyx Single Incision sling by proving its efficacy is persistent over time. Retropubic and transobturator slings have favourable results but require three incisions and blind passage of trocars. This blind needle passage had the potential risk of visceral and vascular damage [7-12]. The use of single incision slings is appealing because of its minimal invasiveness, even less than TVT or TOT slings, and potential for decreasing morbidity.

Single Incision sling technology has been evolving over the last 5 years. Innovations have occurred that have considerably improved the procedure. One of the first single incision slings was the Tissue Fixation System (TFS), which anchors the sling to soft tissue below the pubic bone using two small plastic anchors. Petros et al reviewed 3 year data using the TFS sling and found success rates of $80 \%$ in the 31 patients that were studied [13]. Promising results have also been achieved with the Arcus minisling. In a study of 18 women with SUI, at 12 months $88 \%$ of patients were dry and $5.5 \%$ were improved [14]. An observational series of 76 women treated with the Minitape ${ }^{\circledR}$, demonstrated a $97 \%$ continence rate at 21 weeks [15].

Retrospective data has also been reported on 61 patients with SUI treated at a single centre with the MiniArc single-incision sling [16]. An overall cure rate at 12 months of $91.4 \%$ was reported. There were no intraoperative complications, and there was only one postoperative adverse event secondary to urinary retention.

Lower success rates were reported with the TVT SECUR $^{\circledR}$ mintape. In the TVT SECUR ${ }^{\circledR}$ series of 91 patients, subjective and objective cure rates were $78 \%$ and $81 \%$, respectively, and post-operative complications included voiding difficulty, recurrent UTI, de novo urgency incontinence and dyspareunia [17]. High postoperative continence rates of $95 \%$ have also been reported retrospectively with the Solyx ${ }^{\mathrm{TM}}$ SIS procedure, that are comparable to both the minislings and full-length slings. Unlike the full-length slings, no peri-operative complications or post-operative complications at a mean of 6.5 months follow-up were reported. Patients remarkably did not report any significant pain related to the sling procedure [5].

Additionally, a prospective study looking at the Solyx ${ }^{\mathrm{TM}}$ single incision sling showed that $95 \%$ patients had a successful objective outcome with a negative cough test. The IQOL and UDI scores at both 6 and 12 weeks showed marked statistically significant improvement in the quality of life of these patients, and all patients recorded satisfaction with their surgical outcomes. Additionally, there were no significant intraoperative or postoperative complications. Finally, patients did not report any implant related pain postoperatively, which 
further confirms the minimally invasive nature of the device [6].

In this study, our goal was to look at the efficacy and safety of the Solyx ${ }^{\mathrm{TM}}$ single incision sling over the long term. This paper demonstrates that not only does this single incision sling work well in the short term, but the results are sustainable over a mean follow up of more than 3 years.

Patients in this study did not experience any episode of transient or permanent urinary retention. This finding may be explained by the concept that this sling is placed laterally to the urethra with very little upward force. The lack of compression would suggest that the sling would be unlikely to cause retention or significant voiding dysfunction as is shown in this study.

Among the strengths of this study are its long term data collection and sample size demonstrating efficacy of the Solyx ${ }^{\mathrm{TM}}$ SIS system. Limitations of this study include its retrospective collection of data although this is offset by a prospective phone questionnaire. Larger randomized prospective controlled trials are warranted to confirm the safety and long-term efficacy of the Solyx ${ }^{\mathrm{TM}}$ SIS system.

\section{Conclusion}

This study is unique because it has a mean follow up of 43 months. The findings show that both subjectively by a questionnaire and objectively by a cough test, the Solyx SIS system has sustainable long-term efficacy. This efficacy appears to be comparable to the retropubic and the obturator sling approaches. The placement is achieved through a small single vaginal incision, with minimal tissue disruption, which translates to minimal postoperative discomfort. The lack of postoperative pain, retention, and significant complications, along with its ease of placement, makes this a safe and effective procedure to correct SUI.

\section{Acknowledgements}

This paper was supported by a restricted educational grant from Boston Scientific.

\section{REFERENCES}

[1] U. Ulmsten, P. Johnson and M. Rezapour, “A Three-Year Follow up of Tension-Free Vaginal Tape for Surgical Treatment of Female Stress Urinary Incontinence,” British Journal of Obstetrics and Gynaecology, Vol. 106, No. 4, 1999, pp. 345-350. http://dx.doi.org/10.1111/j.1471-0528.1999.tb08272.x

[2] G. B. Boustead, "The Tension-Free Vaginal Tape for Treating Female Stress Urinary Incontinence,” BJU International, Vol. 89, No. 7, 2002, pp. 687-693. http://dx.doi.org/10.1046/j.1464-410X.2002.02659.x

[3] N. Kuuva and C. G. Nilsson, “A Nationwide Analysis of
Complications Associated with the Tension-Free Vaginal Tape (TVT) Procedure,” Acta Obstetricia et Gynecologica Scandinavica, Vol. 81, No. 1, 2002, pp. 72-77. http://dx.doi.org/10.1034/j.1600-0412.2002.810113.x

[4] P. E. Petros and P. A. Richardson, "Midurethral Tissue Fixation System Sling-A 'Micromethod' for Cure of Stress Incontinence-Preliminary Report,” Australian and New Zealand Journal of Obstetrics and Gynaecology, Vol. 45, No. 5, 2005, pp. 372-375. http://dx.doi.org/10.1111/j.1479-828X.2005.00448.x

[5] S. Serels, M. Douso and G. Short, "Retrospective Review of Early Experience Using the Boston Scientific Solyx ${ }^{\mathrm{TM}}$ Single Incision Sling System to Treat Stress Urinary Incontinence in Women: Intraoperative Experience," International Urogynecology Journal, Vol. 21, No. 5, 2010, pp. 557-561.

[6] S. Serels, S. B. Nosseir, L. R. Lind and H. A. Winkler, "Safety and Efficacy of the Solyx Single-Incision Sling for the Treatment of Stress Urinary Incontinence: Preliminary Results," UroToday International Journal, Vol. 4, No. 1, 2011, art 5. http://dx.doi.org/10.3834/uij.1944-5784.2011.02.05

[7] F. Araco, G. Gravante, R. Sorge, et al., "TVT-O vs TVT: a Randomized Trial in Patients with Different Degrees of Urinary Stress Incontinence,” International Urogynecology Journal and Pelvic Floor Dysfunction, Vol. 19, No. 7, 2008, pp. 917-926.

http://dx.doi.org/10.1007/s00192-007-0554-y

[8] M. Neuman, "TVT and TVT-Obturator. Comparison of Two Operative Procedures,” European Journal of Obstetrics \& Gynecology and Reproductive Biology, Vol. 131, No. 1, 2007, pp. 89-92.

http://dx.doi.org/10.1016/j.ejogrb.2006.03.007

[9] A. Liapis, P. Bakas, M. Giner, et al., "Tension-Free Vaginal Tape versus Tension-Free Vaginal Tape Obturator in Women with Stress Urinary Incontinence," Gynecologic and Obstetric Investigation, Vol. 62, No. 3, 2006, pp. 160-164. http://dx.doi.org/10.1159/000093320

[10] P. Debodinance, "Trans-Obturator Urethral Sling for Surgical Correction of Female Stress Urinary Incontinence: Outside-In (Monarc) versus Inside-Out (TVT-O). Are Both Ways Safe?” Journal de Gynécologie Obstétrique et Biologie de la Reproduction (Paris), Vol. 35, No. 6, 2006, pp. 571-577.

http://dx.doi.org/10.1016/S0368-2315(06)76446-8

[11] T. M. Roth, "Management of Persistent Groin Pain After Transobturator Slings,” International Urogynecology Journal and Pelvic Floor Dysfunction, Vol. 18, No. 11, 2007, pp. 1371-1373. http://dx.doi.org/10.1007/s00192-007-0365-1

[12] D. Waltregny, O. Reul, B. Mathantu, et al. Inside out Transobturator Vaginal Tape for the Treatment of Female Stress Urinary Incontinence: Interim Results of a Prospective Study after a 1-Year Minimum Followup,” Journal of Urology, Vol. 175, No. 6, 2007, pp. 2191-2195. http://dx.doi.org/10.1016/S0022-5347(06)00277-1

[13] P. E. Petros and P. A. Richardson, "Midurethral Tissue Fixation System (TFS) Sling for Cure of Stress Incontinence-3 Year Results,” International Urogynecology 
Journal and Pelvic Floor Dysfunction, Vol. 19, No. 6, 2008, pp. 869-871.

http://dx.doi.org/10.1007/s00192-007-0547-x

[14] P. Palma, C. Riccetto, R. Reges, et al., "Arcus to Arcus Microsling: Technique and Preliminary Results," International Urogynecology Journal, Vol. 19, No. 8, 2008, pp. 1133-1136. http://dx.doi.org/10.1007/s00192-008-0595-x

[15] R. Alinsod and M. Safir, "Initial Outcomes of a Stabilized Adjustable Minisling for Female Urinary Stress Incontinence. Abstract 865,” ICS Annual Congress, San Francisco, 2009.

[16] R. D. Moore, G. K. Mitchell and J. R. Miklos, "Single-Center Retrospective Study of the Technique, Safety, and 12-Month Efficacy of the MiniArc Single-Incision Sling: A New Minimally Invasive Procedure for Treatment of Female SUI," Surgical Technology International, Vol. 18, 2009, pp. 175-181.

[17] M. Meschia, P. Barbacini, V. Ambrogi, et al., "TVTSecur: A Minimally Invasive Procedure for the Treatment of Primary Stress Urinary Incontinence. One Year Data from a Multi-Centre Prospective Trial,” International Urogynecology Journal, Vol. 20, No. 3, 2009, pp. 313-317. http://dx.doi.org/10.1007/s00192-008-0772-y 